American Journal of Applied Sciences 4 (8): 605-612, 2007

ISSN 1546-9239

(C) 2007 Science Publications

\title{
Thermodynamic Profile of Some Heavy Metal Ions Adsorption Onto Biomaterial Surfaces
}

\author{
Medhat A. Shaker \\ Physics \& Chemistry Department, Faculty of Education, \\ Alexandria University, Damanhour, Egypt
}

\begin{abstract}
The adsorption of $\mathrm{Co}^{2+}, \mathrm{Zn}^{2+}, \mathrm{Pb}^{2+}$ and $\mathrm{Hg}^{2+}$ onto dried non-living biomass (NB) of different Pseudomonas strains has been investigated in detail. Maximum adsorption of these cations is achieved at optimum $\mathrm{pH}$ values from 3.5 to 4.5 to avoid hydrolysis, polymerization and precipitation of metal cations in the treatment solutions. The experimental data obtained at different temperatures were fitted to the Langmuir model at different temperatures from 283 to $323 \mathrm{~K}$. Metal ions adsorption occurs in multi detectable steps (i=A, B, C). Binding of $\mathrm{Pb}$ (II) to NB occurs in one detectable step labeled $\mathrm{A}$, where two detectable binding steps were observed for the other cations; $\mathrm{A}$ and $\mathrm{B}$ for $\mathrm{Zn}(\mathrm{II}), \mathrm{A}$ and $\mathrm{C}$ for $\mathrm{Co}(\mathrm{II}), \mathrm{B}$ and $\mathrm{C}$ for $\mathrm{Hg}(\mathrm{II})$, respectively. Site capacities, $\mathrm{v}_{\mathrm{i}}$ are found to be temperature-independent in the whole investigated temperature range. The thermodynamic parameters $\left(\Delta \mathrm{H}_{\mathrm{i}}, \Delta \mathrm{S}_{\mathrm{i}}\right.$ and $\left.\Delta \mathrm{G}_{\mathrm{i}}\right)$ for the adsorption processes were calculated for each binding step $i$ and the results suggest that the nature of adsorption is endothermic and the process is spontaneous and favorable. Thermodynamic data pairs $\left(\Delta \mathrm{H}_{\mathrm{i}}, \Delta \mathrm{S}_{\mathrm{i}}\right)$ for metal binding are linearly correlated for all sites in the investigated biosorption systems.
\end{abstract}

Keywords: Adsorption, Isotherms, Langmuir, Thermodynamic parameters

\section{INTRODUCTION}

Environmental pollution, as a consequence of the industrialization process, is one of the major problems that has to be solved and controlled. Heavy metals are not biodegradable and have become an ecotoxicological hazard of prime interest and increasing significance owing to their harmful effect on human physiology and other biological systems when they exceed the tolerance levels. A number of technologies for the removal of heavy metal ions from aqueous solutions have been developed over the years ${ }^{[1]}$. The most important of these techniques include chemical precipitation, filtration, ion-exchange, and reverse osmosis. However, all these techniques have their inherent advantages and limitations in application. Adsorption is an effective purification and separation technique used in industry especially in water and wastewater treatments. Often, adsorption is used to remove pollutants or toxic materials such as heavy metals from aqueous and non-aqueous solutions. In recent years considerable attention has been devoted to the study of using biomaterials for removal of heavy metal ions from solution by adsorption ${ }^{[2-9]}$. We used before solid biomaterials such as humic acids to adsorb heavy metal cations from aqueous solutions ${ }^{[4,5]}$.

Biomaterials are of special interest and promising for a number of reasons; they possess a variety of functional groups that are capable of removing metal ions to ppb levels, they are cheap and abundant and they are environmentally safe. Several researchers have shown that non-living biomass is utilized to decontaminate metal-bearing wastewaters ${ }^{[10-13]}$. Heavy metal ions sorb onto non-living biomass surfaces ${ }^{[3]}$ and the sorption is greatest at a $\mathrm{pH}$ value that is just slightly more acidic than the $\mathrm{pH}$ at which there is bulk precipitation of the metal hydroxide. As $\mathrm{pH}$ is further raised, once the bulk solubility limit is reached, the sorption is greatly reduced because the metal ion is removed from solution by the bulk precipitation. Thus the maximum biosorption of metal ions is always attained at the optimum $\mathrm{pH}$ value $\mathrm{e}^{[14]}$. Modeling of biosorption processes in single-metal systems has largely been confined to the use of simple adsorption models like Langmuir isotherm equation ${ }^{[3-5,15,16]}$. So far, the Langmuir adsorption isotherm equation is one of the most widely used models to describe the equilibrium behaviors of adsorbate uptake. The Langmuir isotherm equation can be theoretically derived based on some fundamental assumptions ${ }^{[17]}$.

This work is a continuation of study of the adsorption of heavy metals from aqueous solution onto solid dry and clean biomaterials $s^{[3-5]}$. The thermodynamic functions and adsorption isotherms for 
$\mathrm{Co}^{2+}, \mathrm{Zn}^{2+}, \mathrm{Pb}^{2+}$ and $\mathrm{Hg}^{2+}$ onto non-living biomass (NB) of different Pseudomonas strains from their aqueous solutions are investigated to explore the possible mechanism of the metal binding to the inactive biomass surface.

\section{MATERIALS AND METHODS}

Chemicals and reagents: All chemicals used were analytical reagent grade. Aqueous metal solutions were prepared by dissolving appropriate quantities of reagent grade metal nitrate or chloride salts. Doubly deionized water was used throughout. The $\mathrm{pH}$ was adjusted by appropriate amounts of concentrated nitric acid.

Preparation of non living biomass: The Pseudomonas strains used in the experiments were isolated from western Alexandria sewage treatment plant, Alexandria, Egypt. The strains were characterized as described before ${ }^{[3,18]}$ as Pseudomonas fluorrescens and were prepared for adsorption experiments. Bacterial cells were harvested by centrifugation at $25^{\circ} \mathrm{C}$ for 15 minutes and washed twice with distilled water. The sun-dried biomass was treated with a solution of $\mathrm{H}_{2} \mathrm{SO}_{4}$ $(2 \mathrm{~N})^{[19]}$. The resulting metal-free non living biomass was washed with deionized water several times and thereafter dried at $80^{\circ} \mathrm{C}$ for $24 \mathrm{~h}$. The biomass was further freeze-dried at $0^{\circ} \mathrm{C}$ and reduced pressure and was used as a biosorbent.

Metal binding experiments: The metal adsorption experiments were performed as single component adsorption systems for simplicity under optimum conditions. The metal binding experiments were conducted within the $\mathrm{pH}$ range $3.5-4.5$, Fig. (1), at 10.0, $20.0,30.0,40.0$ and $50.0^{\circ} \mathrm{C}$. This acidic value of $\mathrm{pH}$ was suitable to prevent metal cation hydrolysis, polymerization and precipitation in the treatment solutions, and to neutralize anionic NB functional groups to minimize double layer effects. All the metalNB products could be washed at ambient temperature because of the very slow release of bound metal cations $^{[20]}$.

To determine the maximum metal binding capacity of the NB to sequester certain heavy metal ion from an aqueous solution, fifty milligrams aliquots of freezedried NB were hydrated with water at the working $\mathrm{pH}$ for $24 \mathrm{~h}$ at room temperature and then centrifuged for $15 \mathrm{~min}$ at $10000 \mathrm{rpm}$ to remove excess water. Several metal ion solutions with standard concentrations ranging from zero to $100.0 \mathrm{mM}$ were made from HPLC - analytical grade standards of each metal cation
$\left(\mathrm{Co}^{2+}, \mathrm{Zn}^{2+}, \mathrm{Pb}^{2+}\right.$ and $\left.\mathrm{Hg}^{2+}\right)$. The sets of metal solutions made separately were adjusted to the appropriate $\mathrm{pH}$ value for each metal with concentrated nitric acid. The hydrated NB aliquots were then shaken for $24 \mathrm{~h}$ at the working temperature with $50.0 \mathrm{ml}$ of each set of the investigated metal solutions. Equilibrium was achieved within $24 \mathrm{~h}$ in all cases, as previously observed ${ }^{[3,18]}$. At the equilibrium point the amount of metal remaining in solution became time invariant. The supernatants were analyzed for the corresponding metal cation using flame atomic absorption spectrometer (Perkin Elmer Analyst 300) using a specific lamp for each metal and at a specific wavelength.

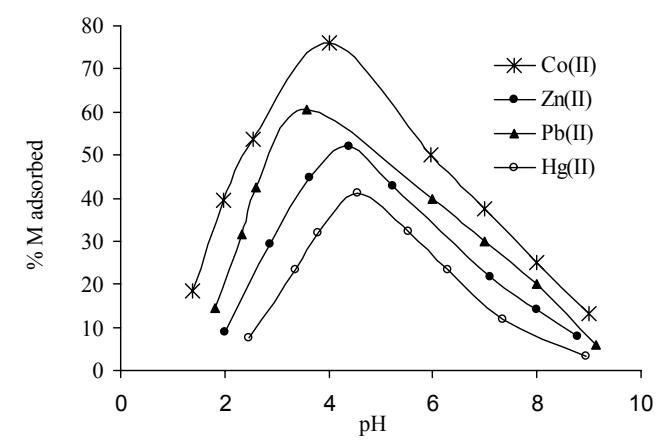

Fig. 1: Effect of $\mathrm{pH}$ on metal adsorption.

Procedure: The mmol bound metal $\mathrm{g}^{-1} \mathrm{NB}$, A, was used with the total mmol metal present to calculate the equilibrium metal concentration c. Langmuir equation (1) predicts that an isotherm of $A_{i}$ vs. c will curve toward the c-axis with increasing c, Fig. (2). Here, $A_{i}$ is the amount of metal bound in binding step $\mathrm{i}(\mathrm{mmol}$ metal $\mathrm{g}^{-1} \mathrm{NB}$ ), $\mathrm{c}$ is the equilibrium metal concentration $(\mathrm{mM}), \mathrm{K}_{\mathrm{i}}$ is the conditional equilibrium binding constant and $v_{i}$ is the stoichiometric capacity of step $i$ for the given metal (mmol metal g $\mathrm{g}^{-1} \mathrm{NB}$ ). The Langmuir model, represented by Eqs. (1)-(3) fits data for metal binding by solid NB.

$$
\begin{aligned}
& A_{i}=\frac{K_{i} v_{i} c}{1+K_{i} c} \\
& \frac{1}{A_{i}}=\frac{1}{v_{i}}+\frac{1}{K_{i} v_{i} c} \\
& \frac{c}{A_{i}}=\frac{c}{v_{i}}+\frac{1}{K_{i} v_{i}}
\end{aligned}
$$

The number of binding steps is revealed when a plot of c/A vs. c, Eq. (3), is made, Fig. (3) ${ }^{[3-5,18]}$. The values of $K_{i}$ and $v_{i}$ for each binding step can be calculated from 
the intercept and slope of linear plots of $1 / \mathrm{A}_{\mathrm{i}}$ vs. $1 / \mathrm{c}$, Eq. (2), Fig. (4).
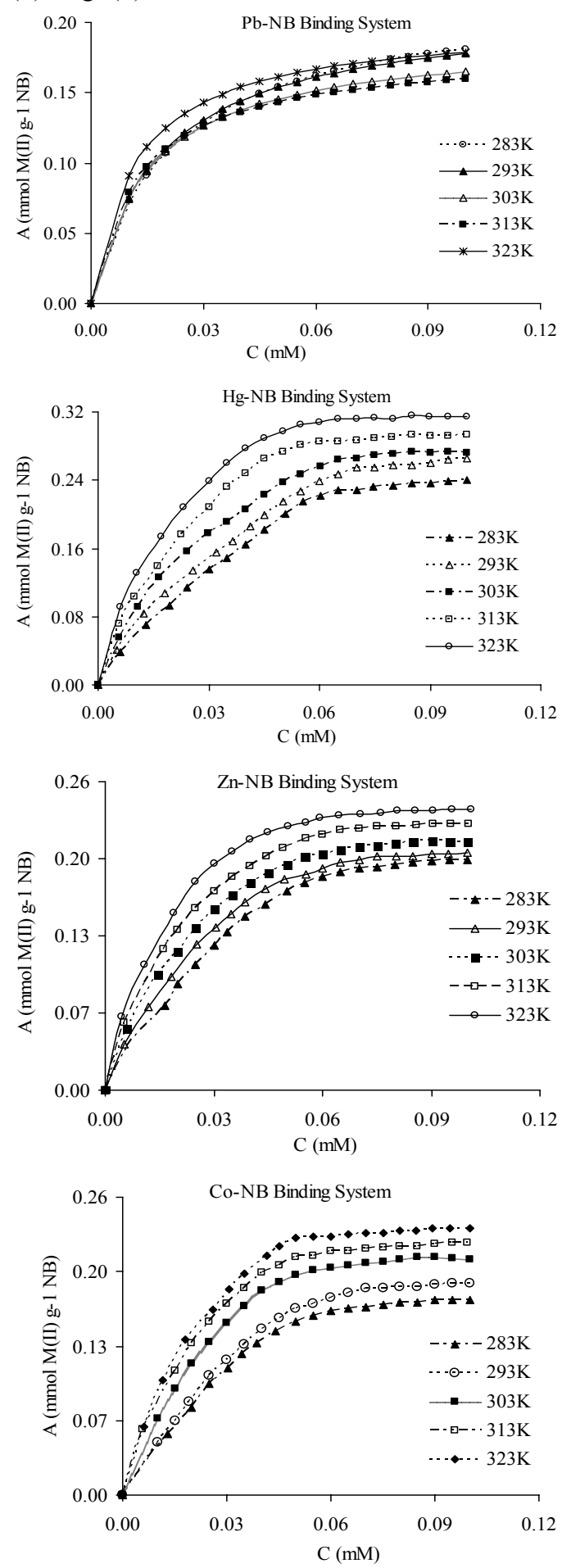

Fig. 2: The isotherms observed for the investigated systems at different temperatures.
All of the points lying on a straight line in a $\ln \mathrm{K}_{\mathrm{i}}$ vs. $1 /$ T plot, Eq. (4), Fig. (5) is taken to mean that a metal cation binds to the same average site $\mathrm{i}$ in a solid NB over the experimental temperature range. The slope and intercept allow calculation of the enthalpy $\left(\Delta \mathrm{H}_{\mathrm{i}}\right)$ and entropy $\left(\Delta \mathrm{S}_{\mathrm{i}}\right)$ changes for metal binding by solid NB from Eq. (4).

$$
\log K_{i}=-\frac{\Delta H}{2.303 R T}+\frac{\Delta S}{2.303 R}
$$

A linear regression computer programme with one independent variable was used for slope analysis and for the statistical treatment of the data ${ }^{[21]}$. The correlation coefficient $\left(\mathrm{R}^{2}\right)$ for all regression analyses was above 0.95 .

\section{RESULTS AND DISCUSSION}

Effect of pH on biosorption of metal cations: NB act as surfaces that can open and close and they are flexible biomolecules whose conformations, aggregation and other properties are affected by environmental conditions such as $\mathrm{pH}$, ionic strength, temperature. The effect of the solution $\mathrm{pH}$ on the adsorption of metal cations onto NB was tested by using $100 \mathrm{~mL}$ aliquots of $10-100 \mathrm{mmol} \mathrm{L}^{-1}$ of each metal solution. The NB biosorption capacities increased with increasing $\mathrm{pH}$ up to optimum $\mathrm{pH}$ value and then decreased at higher $\mathrm{pH}$ values, Fig. (1). In the present study, as shown in Fig. (1), the optimum $\mathrm{pH}$ values for biosorption of $\left(\mathrm{Co}^{2+}\right.$, $\mathrm{Zn}^{2+}, \mathrm{Pb}^{2+}$ and $\mathrm{Hg}^{2+}$ ) were 4.0, 4.4, 3.6 and 4.7, respectively. At the optimum $\mathrm{pH}$ value, electrostatic interactions between cationic species and the negatively charged biomass functional groups are responsible for metal binding ${ }^{[22]}$. The mechanism of the metal uptake$\mathrm{pH}$ dependence might be related to the nature of the cell surface binding sites and to the solution chemistry of metals in water. At low $\mathrm{pH}$, cell wall ligands were closely associated with the hydronium ions $\mathrm{H}_{3} \mathrm{O}^{+}$and restricted the approach of metal cations as a result of the repulsive force. As the $\mathrm{pH}$ increased, more ligands would be exposed and carried negative charges, with subsequent attraction of metallic ions with positive charge and biosorption onto the cell surface ${ }^{[23]}$. The uptake decrease at a much higher $\mathrm{pH}$ may be due to the occurrence of metal precipitation. The NB surface contains mainly carboxyl functional group ${ }^{[24,25]}$ so that the cell walls are negatively charged under acidic $\mathrm{pH}$ conditions with a high affinity for metal ions in solution $^{[23,25,26]}$. 
Am. J. Applied Sci., 4 (8): 605-612, 2007
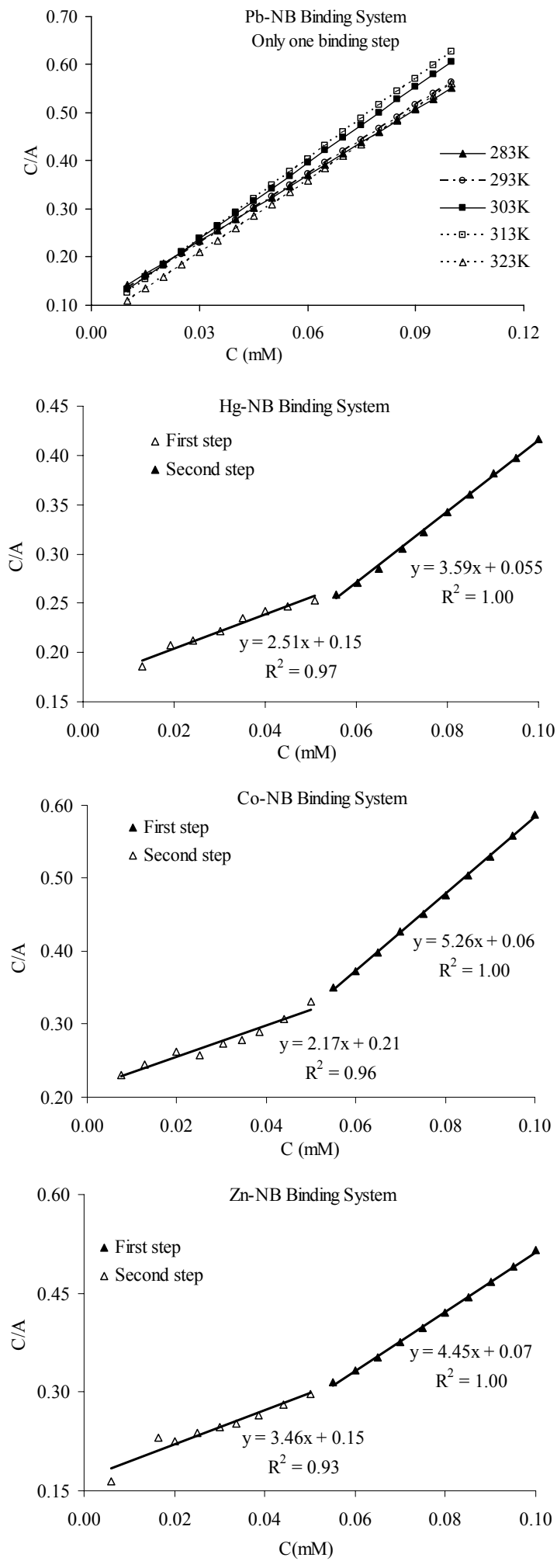

Fig. 3: Some plots of Eq. (3) for the investigated systems

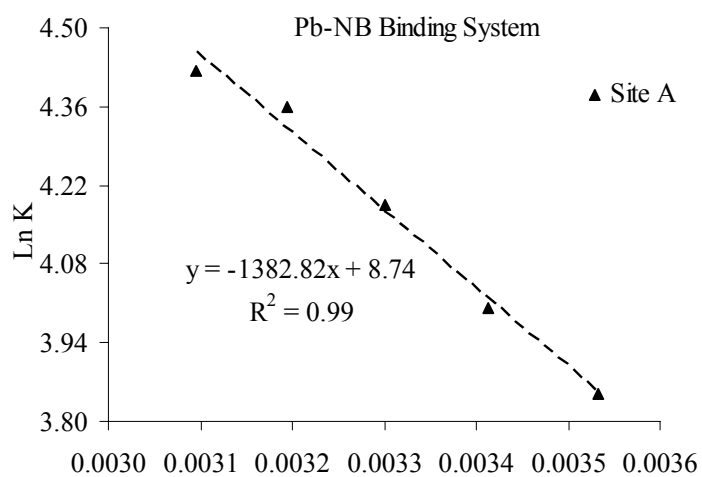

$1 / \mathrm{T}$
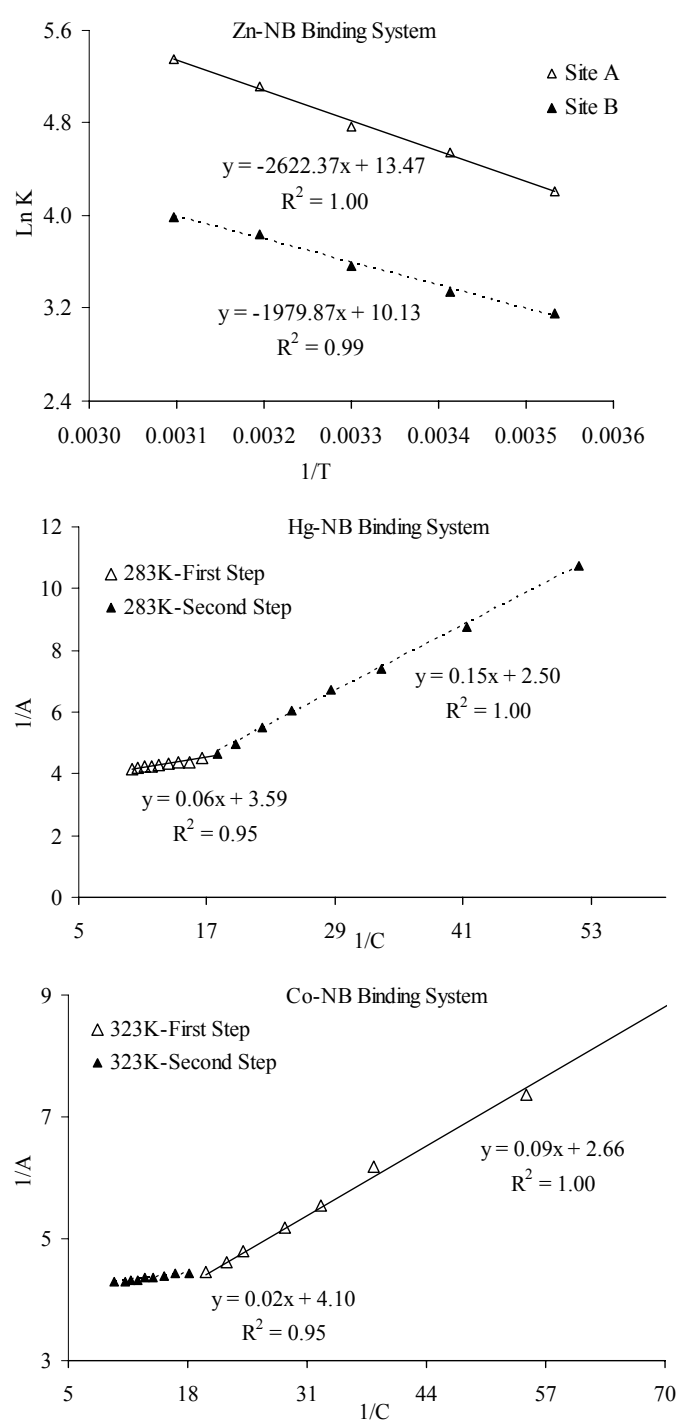

Fig. 4: Plots of equation (2) for some data in Fig. (2). 
Am. J. Applied Sci., 4 (8): 605-612, 2007

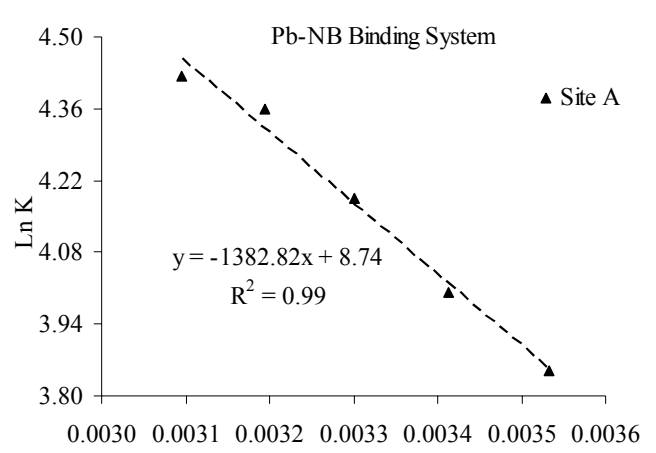

$1 / \mathrm{T}$
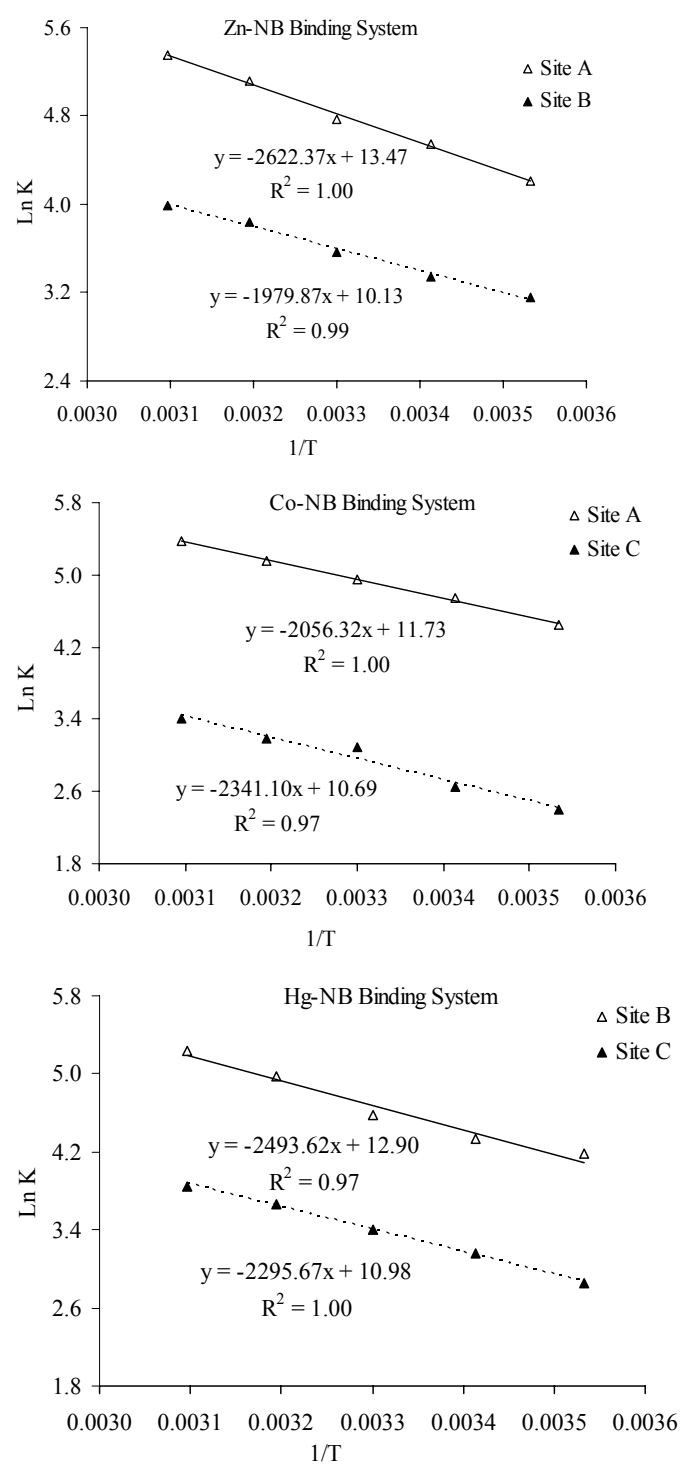

Fig. 5: Effect of temperature on the equilibrium constants for the different surface sites.
Metal binding studies: The Langmuir adsorption isotherm ${ }^{[27]}$ is perhaps the most widely used model due to its simplicity and strong theoretical reasoning behind. As seen in the isotherms (Fig. (2)), the data converge to horizontal plateaus. Each plateau corresponds to the formation of a monolayer of adsorbent on the NB surface. The applicability of the Langmuir isotherm (Eq. (1)) to the obtained data can be examined from the linearity of the plots of c/A vs. c (Eq. (3)). The Adsorption data for these systems are found to fit the Langmuir model within the studied experimental conditions. The site capacities, $v_{i}$ and conditional equilibrium constants, $\mathrm{K}_{\mathrm{i}}$ for $\mathrm{Co}(\mathrm{II}), \mathrm{Zn}$ (II), $\mathrm{Pb}$ (II) and $\mathrm{Hg}$ (II) binding by solid NB at each temperature are collected in Table (1). The site capacities in Table (1) represent the amount of metal bound at equilibrium to the binding sites. The binding reaction is then stoichiometric. Eq. (5) corresponds to inner-sphere ligand exchange with the release of aquo ligands.

$$
\left[\mathrm{M}\left(\mathrm{H}_{2} \mathrm{O}\right)_{m}\right]^{n+}+n \mathrm{RCOO}_{(S)}^{-} \leftrightarrow\left[M\left(\mathrm{H}_{2} \mathrm{O}\right)_{m-n}\left(\mathrm{RCOO}_{n}\right]_{(S)}+n \mathrm{H}_{2} \mathrm{O}\right.
$$

Linear plots of Eq. (2), Fig. (4) indicated multi-binding steps, $\mathrm{i}$ where $\mathrm{i}=\mathrm{A}, \mathrm{B}$ and $\mathrm{C}$. In these plots, linear segments of positive intercepts with excellent $R^{2}$ values are observed which are indicative of how many steps are involved in the binding process ${ }^{[3-5,18]}$. The examination of the adsorption data revealed three different binding sites labeled $\mathrm{A}, \mathrm{B}$ and $\mathrm{C}$. Their capacities $\left(v_{\mathrm{A}}, v_{\mathrm{B}}\right.$ and $\left.v_{\mathrm{C}}\right)$ are $0.20 \pm 0.02,0.30 \pm 0.02$, and $0.40 \pm 0.02 \mathrm{mmol} \mathrm{g}^{-1}$, respectively. If the calculated site capacity $\left(v_{\mathrm{i}}\right)$ of site $\mathrm{i}$ for the investigated systems approaches one of those values the given metal cations bind selectively to this site. The trends of the site capacities to increase on going from step A to B to C and of the equilibrium constants to decrease from step A to B to C are seen for all systems. Isotherms for $\mathrm{Pb}$ (II) binding by solid NB gave one linear segment plot of 1/A vs. 1/c (Eq. (2)) at each temperature indicating one binding step, A. Its site capacity $v_{A}$ varied little with temperature within the experimental error. Table (1) shows that the value of $\mathrm{v}_{\mathrm{A}}$ is averaged to give $0.2 \pm 0.02 \mathrm{mmol} \mathrm{Pb}(\mathrm{II}) \mathrm{g}^{-1} \mathrm{NB}$. The conditional equilibrium constant $\mathrm{K}_{\mathrm{A}}$ for $\mathrm{Pb}$ (II) binding varies with temperature. Two binding steps labeled $\mathrm{A}$ and $\mathrm{B}$ were found for $\mathrm{Zn}$ (II) system at each temperature, Fig. (4). Their site capacities $v_{A}$ and $v_{B}$ were $\left(v_{A}\right)=0.21 \pm 0.01$ and $\left(\mathrm{v}_{\mathrm{B}}\right)=0.30 \pm 0.01 \mathrm{mmol} \mathrm{Zn}(\mathrm{II}) \mathrm{g}^{-1} \mathrm{NB}$, respectively. While for the Co(II) system, two binding steps 
Am. J. Applied Sci., 4 (8): 605-612, 2007

Table 1: Tight binding isotherm parameters at optimum $\mathrm{pH}$ values and different temperatures.

\begin{tabular}{|c|c|c|c|c|c|c|c|c|c|c|c|c|c|c|}
\hline \multirow{3}{*}{$\mathrm{T}\left({ }^{\circ} \mathrm{C}\right)$} & \multirow{2}{*}{\multicolumn{2}{|c|}{$\begin{array}{l}\mathrm{Pb}(\mathrm{II}) \\
\text { Site A }\end{array}$}} & \multicolumn{4}{|c|}{$\mathrm{Co}(\mathrm{II})$} & \multicolumn{4}{|c|}{$\mathrm{Zn}(\mathrm{II})$} & \multicolumn{4}{|c|}{$\mathrm{Hg}(\mathrm{II})$} \\
\hline & & & \multicolumn{2}{|c|}{ Site A } & \multicolumn{2}{|c|}{ Site $C$} & \multicolumn{2}{|c|}{ Site A } & \multicolumn{2}{|c|}{ Site B } & \multicolumn{2}{|c|}{ Site B } & \multicolumn{2}{|c|}{ Site $C$} \\
\hline & $v_{\mathrm{A}}$ & $\mathrm{K}_{\mathrm{A}}$ & $v_{\mathrm{A}}$ & $\mathrm{K}_{\mathrm{A}}$ & $v_{\mathrm{C}}$ & $\mathrm{K}_{\mathrm{C}}$ & $v_{\mathrm{A}}$ & $\mathrm{K}_{\mathrm{A}}$ & $v_{\mathrm{B}}$ & $\mathrm{K}_{\mathrm{B}}$ & $v_{\mathrm{A}}$ & $\mathrm{K}_{\mathrm{A}}$ & $v_{C}$ & $\mathrm{~K}_{\mathrm{C}}$ \\
\hline 10 & 0.22 & 46.9 & 0.19 & 85.6 & 0.42 & 11.1 & 0.22 & 67.4 & 0.29 & 23.5 & 0.28 & 65.3 & 0.40 & 17.3 \\
\hline 20 & 0.21 & 54.7 & 0.20 & 115.5 & 0.38 & 14.1 & 0.22 & 93.7 & 0.29 & 28.3 & 0.30 & 75.8 & 0.38 & 23.6 \\
\hline 30 & 0.19 & 65.8 & 0.22 & 140.4 & 0.38 & 21.8 & 0.21 & 118.1 & 0.29 & 35.5 & 0.30 & 96.7 & 0.38 & 30.1 \\
\hline 40 & 0.18 & 78.3 & 0.23 & 171.8 & 0.39 & 24.3 & 0.21 & 167.1 & 0.29 & 46.7 & 0.32 & 144.0 & 0.39 & 39.1 \\
\hline 50 & 0.20 & 83.3 & 0.23 & 215.8 & 0.38 & 30.2 & 0.22 & 211.8 & 0.30 & 54.1 & 0.32 & 186.8 & 0.42 & 47.2 \\
\hline
\end{tabular}

The site capacity, $v_{i}$, in $\mathrm{mmol} \mathrm{g}^{-1}$, The equilibrium constant, $\mathrm{K}_{\mathrm{i}}$, in $\mathrm{L} \mathrm{mmol}^{-1}$

$A$ and $C$ were found with binding capacities $\left(\mathrm{v}_{\mathrm{A}}\right)=0.21$ \pm 0.02 and $\left(v_{C}\right)=0.40 \pm 0.02 \mathrm{mmol} \mathrm{Co}$ (II) $\mathrm{g}^{-1} \mathrm{NB}$, respectively. The results for the two $\mathrm{Hg}(\mathrm{II})$-binding steps labeled $B$ and $C$ were $\left(v_{B}\right)=0.30 \pm 0.02$ and $\left(v_{C}\right)$ $=0.40 \pm 0.02 \mathrm{mmol} \mathrm{Hg}(\mathrm{II}) \mathrm{g}^{-1} \mathrm{NB}$, respectively.

Comparison of metal binding capacities: The difference in equilibrium constants values, $\mathrm{K}_{\mathrm{i}}$ for binding of metals to surface sites can be explained in terms of the difference in the effective radius of the hydrated metal ions, the nature and distribution of active sites on the biomass and the mode of interaction between metal ions and the biomass. It was observed that metal cations of large ionic potential bind strongly to surface sites. Accordingly, the equilibrium constant values, $\mathrm{K}_{\mathrm{A}}$ which measure the binding affinity of site $\mathrm{A}$ for metals decreases in the order $\mathrm{Co}$ (II) $>\mathrm{Zn}$ (II) $>$ $\mathrm{Pb}(\mathrm{II})$, Table (1). The binding affinity of site $\mathrm{B}$ for metals decreases in the order $\mathrm{Hg}$ (II) $>\mathrm{Zn}$ (II) while the binding affinity of site $\mathrm{C}$ decreases in the order $\mathrm{Hg}(\mathrm{II})>$ Co(II), Table (1). For sites B and C, the soft cation, mercury binds easier than the intermediate cations zinc and cobalt. Soft metals tend to bind with more covalent bonds to these sites, forming inner sphere complexes in which both the NB ligands and metal ions are completely or partially dehydrated. While, hard or intermediate metal cations can bind preferentially to NB surface by electrostatic interactions with hard oxygen ligating atoms to form outer sphere complexes in which the metal cations remain partially hydrated. However, the actual chemical interaction between the metal ion and functional groups on the NB surface was complex and difficult to understand.

Thermodynamic studies: It is clear from the data in Table (1) that the adsorption equilibrium constant, $\mathrm{K}_{\mathrm{i}}$ increases as temperatures vary from 10 to $50^{\circ} \mathrm{C}$ indicating that the adsorption processes are endothermic, Table (2). The metal ions have to displace more than one water molecule for their adsorption and this results in the endothermicity of the adsorption process. The positive value of $\Delta \mathrm{S}$ suggests increased randomness at the solid/solution interface with some structural changes in the adsorbate and adsorbent and an affinity of the NB towards metal cations. $\Delta G$ values were negative indicating the feasibility and spontaneity of the adsorption process. Given that the metal ions are binding to the same sites, then it must be some property of the cations that is responsible for the order of reactivity, the importance of $\Delta \mathrm{S}$ and the correlation between $\Delta \mathrm{H}$ and $\Delta \mathrm{S}$. Surely the most likely explanation is that the difference between the cations is due to the different amounts of water that are released from the metal ion hydration shells when the metal ions are bound to the surface. The increase in disorder caused by the release of these waters would explain the observed behavior, since the degree of order imposed on the aqueous solution by each cation is a function of its charge density. This even explains the correlation of $\Delta \mathrm{H}$ and $\Delta \mathrm{S}$, since for metal cations in aqueous solution, the partial molar entropies are directly correlated with the enthalpies of hydration, and so we would expect the reaction to become more endothermic as $\Delta \mathrm{S}$ increased. Linear plots in Fig. (5) indicate that all $\mathrm{M}$ (II) bind to one average site in solid NB. Enthalpy and entropy changes for binding of the investigated cations by solid NB vary with the metal, Table (2). Positive change in the entropy may be indicative of the strong adsorption of cations to active sites of the adsorbent [29]. The same behavior at all five temperatures supports use of the Langmuir model to describe binding of the investigated metal cations to solid NB. 
Table 2: Thermodynamic parameters for the investigated binding systems.

\begin{tabular}{l|cll}
\hline Binding system & $\begin{array}{c}\Delta \mathrm{H} \\
\text { (kJ mol-1) }\end{array}$ & $\begin{array}{c}\Delta \mathrm{G} \\
\text { (kJ mol-1) }\end{array}$ & $\begin{array}{c}\Delta \mathrm{S} \\
(\mathrm{J} \text { mol-1) }\end{array}$ \\
\hline $\mathrm{Zn}(\mathrm{III})-\mathrm{NB}$ (Site A) & 24.0 & -12.2 & 112.6 \\
$\mathrm{Zn}(\mathrm{II})-\mathrm{NB}$ (Site B) & 21.0 & -9.1 & 98.0 \\
$\mathrm{Co}(\mathrm{II})-\mathrm{NB}($ Site A) & 19.6 & -12.5 & 97.5 \\
$\mathrm{Co}(\mathrm{II})-\mathrm{NB}($ Site C) & 16.2 & -7.5 & 88.9 \\
$\mathrm{~Pb}(\mathrm{II})-\mathrm{NB}($ Site A) & 11.5 & -10.5 & 72.7 \\
$\mathrm{Hg}(\mathrm{II})-\mathrm{NB}($ Site B) & 21.9 & -11.8 & 107.3 \\
$\mathrm{Hg}(\mathrm{II})-\mathrm{NB}($ Site C) & 18.4 & -8.6 & 91.3 \\
\hline
\end{tabular}

The straight line in Fig. (6) has slope $\mathrm{T}=298 \mathrm{~K}$ and intercept $\Delta \mathrm{G}=-9.5 \mathrm{~kJ} \mathrm{~mol}^{-1}$. This linearity confirms the appropriateness of the Langmuir model and strengthens the conclusion of correlated thermodynamic parameters for metal binding by solid NB. The calculated $\Delta \mathrm{G}=-9.5$ $\mathrm{kJ} \mathrm{mol}^{-1}$ means favorable but mildly exergonic metal binding and indicates that solid NB acts as free energy buffer on binding to metals.

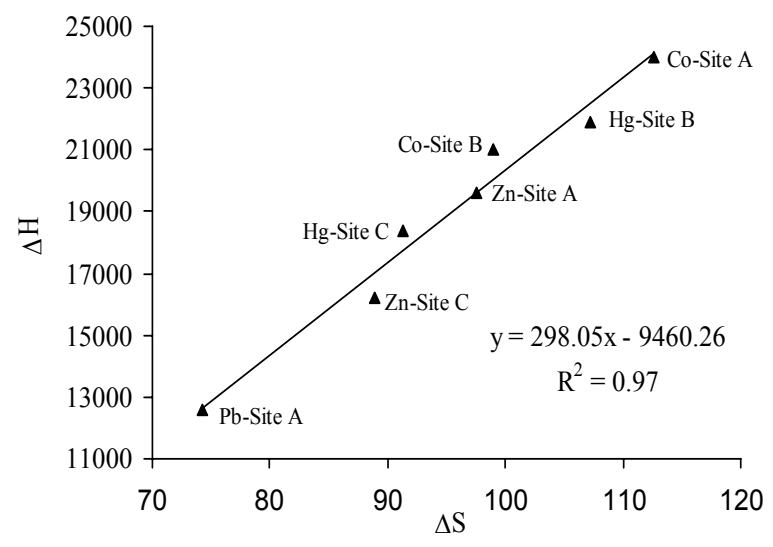

Fig. 6: Correlation of enthalpy and entropy changes for metal binding by NB

\section{CONCLUSION}

At the optimum $\mathrm{pH}$ value, $\mathrm{Pb}$ (II) cations bind in one step to a solid NB isolated from Alexandria sewage treatment plant while $\mathrm{Co}(\mathrm{II}), \mathrm{Zn}(\mathrm{II})$ and $\mathrm{Hg}$ (II) cations bind in two steps. The binding isotherms fit the Langmuir model. The binding affinity order is: $\mathrm{Co}(\mathrm{II})>$ $\mathrm{Zn}(\mathrm{II})>\mathrm{Pb}(\mathrm{II})>\mathrm{Hg}(\mathrm{II})$, Table (2). Metal binding enthalpy and entropy changes fit the linear correlation for the investigated metal cations binding by solid NB, Fig. (6). Free energy buffering resulting from cooperative enthalpy and entropy changes suggests that desolvation of the cations and NB binding sites to allow for inner-sphere complexation is a common requirement for metal binding by solid NB. The temperature variation has been used to compute the values of $\Delta G, \Delta H$ and $\Delta S$. The positive value of $\Delta H$ and negative value of $\Delta G$ indicate endothermic and spontaneous nature of sorption respectively. NB can accommodate different cations with different coordination requirements in sites whose binding affinity depends on the identity of the metal.

\section{ACKNOWLEDGMENT}

The author acknowledges the assistance from $\mathrm{H}$. M. Hussein Institute of Genetic Engineering and Biotechnology, Mubarak City for Scientific Research and Technology, Alexandria, Egypt.

\section{REFERENCES}

1. Romero-Gonzales, M. E., C. J. Williams and P. H. E. Gardiner. 2001. Study of the mechanisms of cadmium biosorption by dealginated seaweed waste. Environ. Sci. Technol. 35: 3025-3030.

2. Bayat, B.. 2002. Comparative study of adsorption properties of Turkish. fly ashes (I): The case of nickel, copper and zinc. J. Hazard. Materials. 95: 251-273.

3. Shaker M. A. and H. M. Hussein. 2005. Heavymetal adsorption by non-living biomass. Chem. Ecolol. 21: 303-311.

4. Ghabbour, E. A., M. A. Shaker, A. El-Toukhy, I. M. Abid and G. Davies. 2006. Thermodynamics of metal cation binding by a solid soil-derived humic acid: Binding of $\mathrm{Fe}(\mathrm{III}), \mathrm{Pb}(\mathrm{II})$, and $\mathrm{Cu}(\mathrm{II})$. Chemosphere. 63: 477-483.

5. Ghabbour, E. A., M. A. Shaker, A. El-Toukhy, I. M. Abid and G. Davies. 2006. Thermodynamics of metal cation binding by a solid soil derived humic acid. 2. Binding of $\mathrm{Mn}(\mathrm{II}), \mathrm{Co}\left(\mathrm{NH}_{3}\right)_{6} \mathrm{aq}^{3+}$ and $\mathrm{Hg}(\mathrm{II})$. Chemosphere. 64: 826-833.

6. Bailey, S. E., T. J. Olin, R M. Bricka and D. D. Adrian. 1999. A review of potentially low-cost sorbents for heavy metals.Water Res. 33: 24692479.

7. Manning, B. A. and S. Goldberg. 1997. Adsorption and stability of arsenic (III) at the clay mineralwater interface. Environ. Sci. Technol. 31: 20052011.

8. Sarkar, A. R., P. K. Data and M. Sarkar. 1996. Data on the adsorption kinetics of heavy metal ions by various sorbents. Talanta. 43: 1857-1862.

9. Brajter, K. and E. Dabek-Zlotorzynska. 1990. Separation of metal ions on a modified aluminium oxide. Talanta. 37: 613-618.

10. Sekhar, K. C., C. T. Kamala, N. S. Chary and Y. Anjaneyulu. 2003. Removal of heavy metals using a plant biomass with reference to environmental control. Int. J. Miner. Process. 68: 37-45. 
11. Arica, M. Y., C. Arpa, G. Bayramoglu and O. Genc. 2003. Ca-alginate as a support for $\mathrm{Pb}(\mathrm{II})$ and Zn(II) biosorption with immobilized Phanerochaete chrysosporium. Carbohyd. Polym. 52: 167-174.

12. Volesky, B. 2001. Detoxification of metal-bearing effluents: Biosorption for the next century. Hydrometallurgy. 59: 203-216.

13. Tobin, J. M. and J. C. Roux. 1998. Mucor biosorbent for chromium removal from tanning effluent. Water Res. 32: 1407-1416.

14. Marjeta, K., S. Janez and M. Svetozar. 1995. Characterization of chromium and copper complexes with fulvic acids isolated from soils in Slovenia. Sci. Total Environ. 159: 23-31.

15. Aldrich, C. and D. Feng. 2000. Removal of heavy metals from wastewater effluents by biosorptive flotation. Miner. Eng. 13: 1129-1138.

16. Ho, Y. S. and G. McKay. 1999. The sorption of lead(II) ions on peat. Water Res. 33: 578-584.

17. Morel, F. M. M. and J. P. Hering, 1993. Principles and Applications of Aquatic Chemistry: Wiley, New York, pp 12-28.

18. Hussein, H. M., M. A. Shaker and A. E. Ali. 2004. Site Occupation in the biosorption of some heavy metal ions by non-living Pseudomonas SPP. N. Egypt J. Microbiol., 7: 151-160.

19. Sangyun, Y., D. G. Park, J. M. Park and B. Volesky. 2001. Biosorption of trivalent chromium on the brown seaweed biomass. Environ. Sci. Technol. 35: 4353-4358.

20. King, S. J., P. Warwick, A. Hall and N. D. Bryan. 2001. The dissociation kinetics of dissolved metalhumate complexes. Phys. Chem. Chem. Phys. 3: 2080-2085.
21. Saeed, M. M., A. Rusheed, N. Ahmed and J. Tolgyessy. 1994. Extraction and Adsorption Behavior of $\mathrm{Co}(\mathrm{II})$ on HTTA-Impregnated Polyurethane Foam. Sep. Sci. Technol. 29: 21432160.

22. Kuyucak, N. and B. Volesky. 1988. Biosorbents for Recovery of Metals from Industrial Solutions. Biotech Lett. 10: 137-142.

23. Brad, D. and J. R. Duncan. 1994. Bioaccumulation of metal cations by Saccharomyces cerevisiae. Appl. Microhiol. Biotechnol. 41: 149-154.

24. Beveridge, T. J. and R. G. E. Murray. 1976. Uptake and retention of metals by cell walls of Bacillus subtilis. J. Bacteriol. 127: 1502-1518.

25. Beveridge, T. J. and R. G. E. Murray. 1980. Sites of metal deposition in the cell wall of Bacillus subtilis. J. Bacteriol. 141: 876-887.

26. Beveridge T. J. 1989. Role of cellular design in bacterial metal accumulation and mineralization. Ann. Rev. Microbiol. 43: 147-171.

27. Langmuir, I. 1918. The adsorption of gases on plane surfaces of glass, MICA and platinum. J Am Chem. Soc. 40: 1361-1403.

28. Raymon, C. 1988. Chemistry: Thermodynamic. McGraw-Hill, Boston. pp 737-789.

29. Luo, C. and S. Huang. 1993. Adsorption of copper ion with metal hy-. droxide from ammonia solution. Sep. Sci. Technol. 28: 1253-1272. 